\title{
ANALYSIS OF THE AÇAI PRODUCTIVE FLOW IN THE MUNICIPALITY OF ANORI - AMAZONAS
}

\section{${ }^{1}$ Karla Jady Albuquerque de Lima, ${ }^{1}$ Mauro Cezar Aparício de Souza, ${ }^{1}$ Alexandra Priscilla Tregue Costa and ${ }^{2,}$ David Barbosa de Alencar}

\author{
${ }^{1}$ Academic department, University Center FAMETRO, Amazon-Brazil \\ 2Institute of Technology and Education Galileo of Amazon (ITEGAM), Brazil
}

\section{ARTICLE INFO}

\section{Article History:}

Received $17^{\text {th }}$ March, 2020

Received in revised form

$08^{\text {th }}$ April, 2020

Accepted $20^{\text {th }}$ May, 2020

Published online $29^{\text {th }}$ June, 2020

\section{Key words:}

Açaí, Quality management, Logistics, Productive chain.

\section{*Corresponding author:}

David Barbosa de Alencar

\begin{abstract}
Açaí is becoming an important economic factor in the Amazon region, due to the full use of the product; the beaten fruit is transformed into açaí, rich in beneficial properties for our organism, the pits serve as fertilizer, from the stem, the hearts of palm are removed, the roots are used for medicinal purposes, the leaves and peels serve as raw material for crafts and the like. Based on these factors, we propose to investigate the production flow of açaí, in order to analyze the production and distribution logistics process of açaí produced in the municipality of Anori-Am, as it is a growing hub in this sector that has been gaining space in the market for the quality of the product offered. This research is based on theoretical assumptions, described in books and published articles, which justified our idea about the work developed. As a methodology we used exploratory research, where we did bibliographic studies, case studies and data collections that strengthened the data described here with true facts. It is a qualitative and quantitative research, since we analyze both the quality of the product and the increasing percentage of production, as well as the management of logistics components applied to the açaí production chain. Between the lines of this article, readers will be able to obtain information on the nutritional values added to açaí, as well as the functionality of all segments that make up the entire production chain, from cultivation, harvesting, processing, storage and marketing.
\end{abstract}

Copyright (C) 2020, Karla Jady Albuquerque de Lima et al. This is an open access article distributed under the Creative Commons Attribution License, which permits unrestricted use, distribution, and reproduction in any medium, provided the original work is properly cited.

Citation: Karla Jady Albuquerque de Lima, Mauro Cezar Aparício de Souza, Alexandra Priscilla Tregue Costa and David Barbosa de Alencar.

"Analysis of the açai productive flow in the municipality of anori - amazonas", International Journal of Development Research, $10,06,36863-36872$.

\section{INTRODUCTION}

A produção de polpa de Açaí no Estado do Amazonas, especialmente no município de Anorí é um desafio constante considerando as proporções dos insumos disponíveis na extensão da floresta, fazendo com que seja um ponto preocupante para os gestores públicos e consumidores particulares, que têm como principal meta, desenvolver um vasto plantio do fruto, de formas a tornar o município autossustentável, sem destruir e crescer preservando a massa arbórea nativa, bem como melhorar a qualidade das novas plantações do Açaí. A utilização do modelo sócio econômico busca unir pequenos agricultores e produtores rurais do município e do entorno, como forma de expandir o lucro da região bem como capacitar produtivamente cada componente da cadeia produtiva do fruto do Açaí. As estratégias de produção constituem um componente vital para o crescimento da produção, otimizando a utilização dos recursos e planejamento estratégico em pequeno, médio e longo prazo e utilização dos meios corretos de plantio, extração da polpa e profissionalização da atividade na região. Diante desta analogia, detectamos como um problema crucial a falta de planejamento no que tange as estratégias utilizadas quanto ao fluxo de produção do açaí no município de Anori, onde a demanda está em alta e os produtores não estão acompanhando este crescente aumento. Sendo assim, sentiu-se a necessidade de investigarmos os fatores que interferem no fluxo de produção do açaí, já que o produto desta região está se destacando no mercado, porém, ainda se torna incipiente frente a grande demanda da capital e de demais municípios, impedindo-os de alcançarem novos mercados, com o chamado ouro negro da Amazônia. Tivemos como objetivo Geral, analisar o processo de produção e logística de distribuição do açaí produzido no município de Anori-Am. Como objetivos específicos, investigar os fatores que interferem para o possível aumento das áreas de plantio; observar os métodos adotados na questão logística para o escoamento do produto; verificar como são planejadas as escalas de produção e importação do produto para a capital do estado e pontos 
adjacentes; sugestionar um novo modelo de fluxo de produção, com base na realidade local. Para auferir resultados assertivos e coerentes, que proporcionem sugestões de melhoria dos processos analisados, foram utilizadas como ferramentas para aferição de qualidade o Diagrama de Ishikawa, que nos ajudou a levantar causas raízes do problema; o Fluxograma, que nos trouxe um resumo ilustrativo da cadeia produtiva do açaí; e o 5W2H, que está relacionada a ferramenta da gestão de qualidade, que nos levou a elaborar um plano de ação, contendo as sugestões para o melhoramento da qualidade do produto.

\section{FUNDAMENTAÇAO TEORICA}

O Panorama Anoriense e sua Relação com o Açaí: $O$ município de Anori está localizado a margem esquerda do rio Solimões. Sua distância da capital Manaus é de aproximadamente, 234 quilômetros em linha reta, tendo como acesso as vias fluviais. Sua população segundo IBGE (2010) é de 16.317 habitantes, com estimativa para 2019, 21.010 habitantes. $\mathrm{O}$ município se estende por $5.795,3 \mathrm{~km}^{2}$ tendo sua densidade demográfica 2,8 habitantes por $\mathrm{km}^{2}$ no território do município. Vizinho dos municípios de Beruri, Codajás e Anamã, Anori se situa a $46 \mathrm{~km}$ ao Norte-Leste de Codajás a maior cidade nos arredores. Seu clima é tropical chuvoso, úmido e quente, proporcionando um misto de sensações, já que no verão a temperatura se eleva e no inverno, mediante as frequentes chuvas, o clima fica ameno. A história de Anori remete-se em conjunto com a história de seu vizinho. O município de Codajás, quando foi criado através do decreto estadual número 1186, de 31 de dezembro de 1943 o distrito de Anori subordinado a administração de Codajás. Em 29 de dezembro de 1956 foi elevado à categoria de município pela lei estadual $\mathrm{n}^{\circ} 117$, desmembrando-se de seu vizinho e formando o atual município. Seu nome vem da palavra indígena em Nheengatu, "Uanuri" ou "Wanury" regionalmente conhecida como "Ánory", que significa "Tracajá macho", uma espécie de quelônio dulcícola de tom negro azulado com manchas amarelas, na época, facilmente encontrada na região. Sua relação com o açaí surgiu desde a sua criação, onde os ribeirinhos já produziam artesanalmente, o vinho do açaí. Nesta época essa produção era sem fiz comerciais, ou seja, somente para sua própria alimentação, sendo que os excedentes eram distribuídos pela vizinhança ou serviam como moeda de troca.

Nos meados dos anos 60, surgiram os primeiros modelos econômicos, tendo o açaí comercializado no município, porém ainda de forma artesanal. Seus precursores foram: Raimundo Cruz e Sérvulo Dourado Brandão, que devido o plantio de seus açaizais começaram a produzir e comercializar o produto entre os munícipes. Na década de 70, surgiu o primeiro modal industrializado, trazido por Sérvulo Dourado Brandão, pioneiro neste novo empreendimento, onde a escala de produção ampliou-se, agregando valor ao produto e uma margem de comercialização mais sofisticada para a época. A partir daí surgiram novos empreendedores na modalidade industrializada, o que abriu novos horizonte na questão dos investimentos. Surgiram novas máquinas e com isso o modal foi se adequando aos novos tempos, criando novas oportunidades de emprego e renda familiar. De acordo com Yuyama, et al. (2011), na região do Médio Solimões o açaizeiro, palmeira frutífera, denominada Euterpe precatória, é arvore nativa dessa região, cujo fruto, têm grande potencial agronômico, tecnológico, nutricional e econômico.
Esta é uma espécie monocotiledônea nativa da várzea da região amazônica, especificamente dos seguintes países: Colômbia, Venezuela, Equador, Guianas, Peru e Brasil (estados do Amazonas, Amapá, Pará, Maranhão, Rondônia, Acre e Tocantins), assim como de Trinidad e Tobago e das bacias hidrográficas da Colômbia e Equador que desembocam no Oceano Pacífico. Ainda segundo Yuyama et. al (2011) a espécie Euterpe precatória é unicaule, também conhecida como açaí-da-mata, e se encontra fartamente disseminada na bacia do Solimões em terreno de terra firme e área de baixio, e em pequenas propriedades rurais e pomares das cidades. Em Anori, o cultivo do açaí ganhou um novo olhar frente aos investimentos com relação aos commodities X lucros. Partindo desta analogia, passou-se a investir muito mais na produção do açaí com vista na expansão do produto em longa escala, alcançando consumidores de outras regiões, pela qualidade do produto e, consequentemente, alavancando os fluxo produtivo, o que beneficia todos os envolvidos nesta cadeia de produção, desde o agricultor ao revendedores autônomos que são os responsáveis pela viabilidade do produto até a mesa do consumidor.

Para Tavares e Homma, (2013), a cadeia do açaí envolve famílias de extrativistas, produtores, intermediários, pequenas indústrias de beneficiamento, além de um elevado número de batedores artesanais, sendo de importância crucial para a formação de renda de expressivo grupo de famílias de pequenos produtores. Sendo assim, o cultivo do açaí vai muito além de uma colheita aleatória, já que as etapas para se chegar ao produto final precisa ser muito bem orquestrada e alinhada aos demais subgrupos que fazem parte desta cadeia produtiva: O plantio, a colheita, a seleção dos grãos, o transporte, a produção do vinho, o armazenamento, são alguns dos processos que precisam está muito bem planejados, uma vez que um depende da eficácia do outro. Segundo Galotta (2005), além de ser bastante apreciado como alimento, o açaí é muito utilizado na medicina popular: raiz, folhas e talos são muito utilizados nos tratamentos contra dores musculares e picadas de cobra e a folha, para aliviar dores no peito. A raiz também é utilizada no tratamento de enfermidades do fígado e baço, infecções hepáticas e renais. Ainda de acordo com esse autor, os estudos das propriedades físico-químicas demonstraram que a polpa do açaí, contém maiores teores de fenóis, antocianinas e antioxidantes, do que a espécie nativa de outras regiões. Devido aos inúmeros benefícios deste valioso produto, percebeu-se o aumento na demanda de consumidores adeptos ao consumo do suco, assim como das demais partes da árvore com fins a medicinas alternativas. Heinrich et al (2011), afirma que, em levando-se em conta, tais propriedades medicinais, o açaí tem sido amplamente explorado no marketing de bebidas energéticas, considerando-se seu teor elevado de polifenóis, que, por sua vez, está associado às propriedades de antioxidante, anti-inflamatório, antiproliferativo e propriedades cardioprotetoras. Apesar de chamar a atenção por seu alto teor de antocianinas. Tonon, Brabet e Humbinger (2013), afirmam, que várias empresas estrangeiras estão produzindo cápsulas de açaí, considerando os valores medicinais e cuja fruta também é considerada importante fonte de pigmentos naturais, que não apresentam efeitos tóxicos e podem contribuir para a diminuição do uso de outros pigmentos sintéticos nos alimentos. Nos últimos anos, a demanda por açaí entrou de forma expressiva nos mercados nacional e internacional, considerando sua características energéticas, nutritiva, alto teor de fibras e antioxidantes, Para Rogez (2017), o açaí apresenta constituintes nutricionais em seu extrato, com baixa e apesar 
de baixa concentração de proteínas, é rico em energia devido principalmente à presença de lipídios; contudo a presença de potássio e cálcio é sua maior contribuição como produto energético. Diante destes fatores, percebemos que os adeptos de atividades físicas estão vendo no açaí uma grande fonte de energia, principalmente, pós treino onde o produto age como repositor energético após uma longa jornada de exercícios físicos, causando bem estar e relaxamento, além do saciamento da fome em pequenas quantidades consumidas. Yuyama et al (2011) afirma que com o crescimento do mercado da fruta, vem se observando, nos Estados em que é cultivado, em gradual mudança do sistema extrativo que apresenta baixa produtividade para o sistema manejado, porém, com possibilidade de crescer ainda mais com as inovações tecnológicas. Isto pode ser percebido no campo de cultivo, onde antes se plantava pequenos hectares e, hoje, grandes áreas são destinadas ao plantio do açaí e, mesmo assim se torna insuficiente frente à crescente demanda. Com o crescente consumo e encomendas oriundas de outras regiões não produtoras e das exportações para outros Estados, o açaí vem se tornando um cultivo agroindustrial, ainda muito incipiente, porém bastante crescente. No entanto, apesar do aumento das áreas plantadas, a parcela da produção originada pela comunidade é insuficiente para o atendimento da crescente demanda. Nesse contexto, Bentes-Gama (2005), também afirmam que a agregação de valores nutricionais e medicinais associados aos valores socioambientais trazidos pela certificação florestal ou orgânica ampliou o mercado da fruta para além dos mercados. Esse importante receptor do modelo agrícola tem levado a um processo de transformação da floresta, tendendo ao monocultivo da espécie. Para Homma (1993), nessas áreas de florestas inundáveis, os extratores mantêm elevada densidade de indivíduos de açaí com consequente redução da diversidade de espécies arbóreas e da riqueza de espécies nativas. Ainda, quanto a evolução da produção de açaí no Amazonas.

De acordo com Homma (2007), esse processo se encontra numa transição entre a primeira e a segunda fase do modelo macroeconômico. Segundo o autor, parece haver uma tendência de mudança da fase da dominância do extrativismo, no que combinam, extrativismo e plantio. A outra fase, caracteriza-se pelo abandono da coleta e a dominância do plantio doméstico, fatos testificados em setores produtivos já citados. Na afirmação de Clemente et al (2007), esses fatos se assemelham às mudanças, no município de Anori, quando as áreas de cultivos, anteriormente cultivadas com laranjas até áreas limítrofes da estrada do município do Anamã estão sendo convertidas cultivo do açaí. Esse fato se deu em função do abandono dos campos de cultivo de laranjais, por perdas significativas na qualidade do produto e a percepção da crescente demanda pelo açaí. Cuja planta nativa já rendia bons resultados. Além disso, a intensificação da exploração do açaí extrativo nas áreas alagáveis, características do município identificou-se como um no modelo doméstico viável, embora essa espécie ainda esteja restrita aos plantios tradicionais que ocorrem nos chamados sítios ou pomares caseiros. Contrariando o modelo determinístico de Homma (2007), a fase final de substituição do extrativismo pela completa domesticação da espécie em monocultivos para produção comercial, no caso do E. precatória, poderia ser dinamizada pela ampla adoção de práticas melhoradas de coleta e manejo florestal, que levariam ao enriquecimento da espécie nas florestas manejadas.
Há ainda alguns fatores conjunturais a serem considerados para adoção de alternativas tecnológicas inovadoras que são os custos da produção, implantação, etc. Outros fatores externos enfrentados que são históricos na agricultura familiar ribeirinha, como a questão da regularidade fundiária da terra que, segundo Henkel \& Amaral (2008), com o impacto da proximidade da capital e o avanço de fronteira, as práticas vigentes geram aumento do conflito por posse da terra e consequente intensificação o êxodo rural.

A Importância da Logística Para o Cumprimento das Metas Nas Empresas: Para entender logística basta fazermos uma analogia do nosso próprio dia a dia, pois muitas metas são descumpridas por falta de um bom planejamento. Isto nos leva a refletir que, o planejamento das nossas ações se torna fundamental para cumprirmos nossas metas. Nas empresas, esse planejamento precisa estar cronologicamente alinhado para que as metas sejam cumpridas em tempo hábil e satisfatório, tornando um fator essencial para garantir a fidelidade dos clientes. Corroborando com este pensamento, Christofer (2007), destaca que o principal objetivo da Gestão Logística é planejar e coordenar as atividades necessárias para o alcance do nível de qualidade desejado no serviço prestado ao menor custo possível. Nesta linha de pensamento, notamos o quanto a logística eficiente se torna uma importante estratégia para as empresas, principalmente, quando se tem como missão a garantia na qualidade no serviço prestado. Em outras palavras a logística, consiste em fornecer bases para o planejamento estratégico de uma empresa de modo a criar métodos e técnica que possa substanciar o fluxo de abastecimento de insumos, movimentação de mercadoria e estocagem adequada dos produtos. Bowersox; Closs, (2001, p.19) explica que a "Logística é o processo de planejamento, implementação e controle eficiente e eficaz do fluxo e armazenagem de mercadorias, serviços e informações relacionadas, desde o ponto de origem até o ponto de consumo, com o objetivo de atender as necessidades dos clientes". Com um olhar mais abrangente, Gasnier (2002) conceitua logística como uma ação conjunta que necessita está alinhada, pois uma falha em uma das etapas pode causar desajustes nos processos de planejar, executar, controlar o fluxo, armazenagem, matérias primas, entre outros. Isto significa dizer que cada ação tem seu papel importante para que a logística possa ser eficiente e eficaz, para trazer satisfação ao consumidor final, os clientes. Através de planejamento, organização e controle efetivo para as atividades de movimentação e armazenagem, a empresa consegue facilitar o fluxo de produtos provendo melhores lucros e menores perdas (BALOO, 2009). Aos que entendem que a logística eficiente é o "pulo do gato" para garantir o melhor serviço quando se trata de competitividade, elencamos três objetivos essenciais que a logística oferece:

Redução de Custo: $O$ objetivo é reduzir os custos de movimentação e estocagem do produto. Uma das alternativas é fazer uma avaliação quanto ao custo/benefício com a finalidade de detectar possíveis fatores que possam ser entraves, quando se fala em reduzir custos. Às vezes, o realocamento do armazém ou a troca do modal de transporte pode fazer grande diferença na prestação do serviço. Olhar os custos é fundamental na administração logística e isto varia muito de importância de indústria para indústria (DIAS, 2007)

Redução do Capital: $O$ objetivo aqui é maximizar os investimentos sobre o sistema logístico com a finalidade de reduzir custos na empresa. 
A terceirização é uma saída quando se pensa em minimizar o capital, muitas empresas recorrem ao sistema terceirizado para produzir e entregar os produtos em tempo hábil e, com o menor custo devido ao encurtamento do tempo. Fleury (2005), enfatiza que há vários fatores, que estão causando o favorecimento do processo de terceirização logística, dentre eles a proliferação de produtos e maiores exigências de serviços.

Otimização do Serviço: É quando a empresa faz um investimento inicial em sua logística, com a finalidade de reduzir tempo, porém o retorno a longo prazo se torna vantajoso quando o cliente sai satisfeito e começa a fazer Marketing, indicando os serviços aos amigos, parente e familiares aumentando a clientela. Diante do exposto, é possível perceber que a logística é uma das áreas vitais para o desempenho das empresas, se o setor logístico funciona com eficiência a tendência é crescer os serviços e, com clientes satisfeitos a margem de valores aumentam, por outro lado, se este não for a contento, além de se tornar um fator negativo, ainda acarreta prejuízos à empresa, já que na pesquisa de satisfação o resultado tendem a ser negativo. Portanto, empresas bem-sucedidas possuem uma vantagem de custo, uma vantagem de valor, ou, melhor ainda, uma combinação das duas (CHRISTOPHER, 2011) ".

A Expansão Comercial e a Cadeia Produtiva do Açaí: Com a ascensão e a grande perspectiva de bons negócios o açaí se tornou um produto de alto valor comercial, onde os investimentos de empresas de pequeno, médio e grande porte estão tendo um retorno muito mais vantajoso em relação aos demais produtos similares oferecidos no mercado. Buscando um melhor conceito que defina a cadeia produtiva, Arbage (2004) considera que esta é toda atividade realizada dentro de uma logística de produção ligada ao setor primário. Além disso, decorrem da identificação dos principais geradores do sistema agroalimentar. $O$ açaí nos moldes do sistema agroalimentar, possui uma cadeia produtiva bastante particular, onde as áreas de produção ainda são insipientes frente a grande demanda do mercado.

A capital Manaus, hoje, se tornou um grande centro de comercialização do açaí. É notório vermos nas feiras e até mesmo em residências e comércios, tendas com produtos das mais diversas regiões amazônicas. Dentre estas variedades está o açaí produzido em Anori, onde o comercio informal abraçou a comercialização do produto, pela alta margem de lucro oferecido além do retorno no investimento a curto prazo, já que o produto é vendido diariamente, com baixos índices prejuízos por perdas do mesmo. Na afirmação de Souza et. al (2014), a experiência rentável do açaí foi adquirindo destaque pelo aumento da produção e demanda do consumo, que deixou de ser em pequena escalas de produção e começou a ganhar escala industrial do ciclo superior, para começar a atender setores mais promissores e uma expansão lucrativa, deixando de ser exclusivamente de consumo local e passando para exportação do fruto (em forma de polpa ou pasteurizada) para novos mercados consumidores. Neste sentido, a produção do açaí ganhou outro patamar deixando de ser somente um produto rural, para ser um produto nacionalmente reconhecido. Isto se dar pelo fato de sua grande popularidade e dos grandes investimentos das empresas em comercializar este produto, seja de forma in natura ou congelado.
Gestão da Qualidade e suas Principais Ferramentas: Empresas dos mais variados segmentos, já perceberam que produtos e serviços de qualidade as colocam à frente quando se trata de competividade. Oferecer um produto ou serviço onde atenda as expectativas do cliente, se torna um fator crucial para a fidelidade deste público, Para isto, precisa-se traçar metodologias para aferir se esta qualidade no serviço prestado, atende de fato as necessidades e anseios da clientela. $O$ conceito de qualidade é extremamente subjetivo, pois trata-se tanto de uma questão de percepção do cliente, já que o que pode ser eficiente para um, pode não está a contento para outro, quanto de conformidade com as especificações determinadas. Neste contexto Crosby (1986, p. 31) diz que "Qualidade é a conformidade do produto às suas especificações”. No entanto, Deming (1993, p. 56) parte de um ponto de vista mais dinâmico quando afirma que "Qualidade é tudo aquilo que melhora o produto do ponto de vista do cliente".

É importante destacarmos que o emprego de ferramentas da qualidade no processo de produção de um produto ou serviço, com o intuito de atender as necessidades do cliente, compreende uma ação estratégica de grande valia para as empresas, pois no cenário atual os clientes recebem ofertas de inúmeros produtos inovadores todos os dias, e isto exige eficiência no serviço prestados, para conseguir se destacar no mercado e fidelizar sua clientela. Para Campos (2004, p.2) "O verdadeiro critério de boa qualidade é a preferência do consumidor". A percepção de qualidade é separada em diversas dimensões, algumas delas são: desempenho do produto, durabilidade, conformidade com as especificações, atendimento, qualidade percebida, aparência e outras. Para Rezende (2012) as empresas precisam identificar em quais dimensões de qualidade o seu produto pode alcançar a excelência, e assim direcionar suas atenções para elas, no intuito de diferencia-las mediante a concorrência. Cada empresa ou organização, precisa fazer suas análises quanto a qualidade do produto ofertado, para montar um parecer demonstrativo que possa vislumbra a real situação em que sua empresa se encontra e assim, procura sanar as problemáticas apresentadas. Aqui, iremos descrever 5 ferramentas da qualidade que consideramos mais utilizada nas empresas: Histograma, Carta Controle, Diagrama de Ishikawa, Fluxograma de processos e 5W2H.

Histograma: O Histograma é uma ferramenta gráfica que auxilia na verificação de frequência de dados que tem por objetivo identificar como determinada amostra está distribuída. Ele permite interpretar grande volume de dados e visualizar como eventos que se repetem, variam no tempo. A montagem do histograma demanda a escolha de um processo e a definição do indicador de desempenho a ser considerado. Deve-se determinar o período de análise ou a quantidade de dados e realizar os cálculos para posterior construção do histograma. (RODRIGUES, 2010). Sua visualização auxilia na compreensão de casos, como: Quantidade de produtos nãoconformes; Dispersão das medidas de determinado produto; Entre outros.

Carta de Controle: É uma ferramenta gráfica que pode ser visualizada com a finalidade de mostrar as possíveis variáveis que possa ocorrer em determinada etapa de um processo. Para Rodrigues (2010) a carta de controle é uma forma de explicitar o CEP. Nas palavras de Werkema (1995, p. 198) "os gráficos (cartas) de controle são ferramentas para o monitoramento da 
variabilidade e para a avaliação da estabilidade de um processo." A carta de controle foi desenvolvida pelo matemático e estatístico Walter Shewart e por este motivo também é chamada de Carta de Shewart.

Diagrama de Ishikawa: O Diagrama de Ishikawa é uma ferramenta útil para identificar as causas-raízes de um determinado problema. Também conhecido como Diagrama Espinha de Peixe devido ao seu formato semelhante a espinha de um peixe, o diagrama de Ishikawa é uma ótima alternativa para estudar com profundidade as causas de um efeito negativo, levantando todas as possíveis variáveis que influenciam o resultado não esperado. Werkema (1995, p.101) enfatiza que esta, "[...] é uma ferramenta utilizada para apresentar a relação existente entre o resultado de um processo (efeito) e os fatores (causas) do processo que, por razões técnicas, possam afetar o resultado considerado". Este diagrama utiliza variáveis 4M (método, mão-de-obra, material e máquina). Para elaborar um diagrama de causa e efeito é necessário realizar previamente um brainstorming ou alguma outra técnica que envolva equipes de trabalho. (RODRIGUES, 2010). Sendo assim é necessário levantar categorias macros, ou seja, elencar hipóteses para assim tentar encontrar as causas de um problema relacionado a cada categoria definida. Por exemplo, em alguns momentos os gestores podem achar que a causa de um problema na linha produtiva seja o maquinário produtivo. A categoria macro é maquinário, as sub causas seriam a capacidade produtiva das máquinas; as máquinas são antigas, os operadores não são capacitados, mão de obra ineficiente e entre outros elementos. Vale salientar que, o brainstorming (tempestades de ideias), acontece por meio de uma equipe formada por pessoas dentro da empresa, para debaterem sobre as causas de um determinado problema, onde as sugestões são lançadas e discutidas por todos, para se chegar a um denominador comum. Tendo definido o problema e demonstrado por meio do diagrama, o gestor pode elaborar um plano de ação que possa reverter o problema detectado (efeitos). O 5W2H é uma ótima ferramenta para complementar a etapa de planejamento diante das causas levantadas.

Fluxograma de processos: O fluxograma de processos é uma representação gráfica que descreve os passos e etapas sequenciais de um determinado processo. O fluxograma de processos pode ser útil no momento de desenhar os processos e indicar visualmente: $\mathrm{O}$ início e fim de um processo; As atividades de um processo; Os pontos de decisão; Os documentos necessários; O fluxo contínuo de uma informação e etc. Os símbolos usados no fluxograma descrevem e mapeiam as diversas etapas de um processo, de forma ordenada e com uma sequência lógica. Pelo fluxograma podese identificar o tempo, a produtividade, a confiabilidade ou a capacidade do processo. Também é possível identificar erros, duplicidade e tarefas sem valor agregado. (RODRIGUES, 2010). Na prática, o fluxograma descreve um tipo de desenho técnico cujo objetivo principal é expressar o funcionamento de uma atividade de forma objetiva e muito clara. É importante frisarmos que existem regras e normas para se criar um fluxograma, de modo que o demonstrativo traga informações importante, assim como possíveis soluções para os pontos considerados cruciais, para um bom andamento do processo. Vale ressaltar que, o fluxograma traz benefícios aos que dele se utiliza, pois suas principais funções é organizar o pensamento dentro de um gráfico, para serem demonstrados os pontos críticos de uma determinada ação.
Ele pode ser usado em diversas áreas: Educação, venda e marketing, negócios, engenharia, etc.

5W2H: O 5W2H é a principal ferramenta de gestão para elaboração de planos de ação. Através desta ferramenta é possível identificar todos os elementos para execução de um plano seja ele estratégico, tático ou operacional. Apesar de parecer básica, esta ferramenta se mostra muito eficiente, quanto aos resultados obtidos. Ela é útil para traçar um plano de ação independente de sua complexidade. Através dela podemos, por exemplo, desenvolver novos produtos, abrir novas franquias, expandir em novos mercados, analisar concorrências, entre outros. O 5W2H tem como objetivo principal auxiliar no planejamento de ações, pois ele ajuda a esclarecer questionamentos, sanar dúvidas sobre um problema ou tomar decisões.

Seu uso traz benefícios assim como facilidade na compreensão de fatos e um melhor aproveitamento de informações. Isso acontece pois o $5 \mathrm{~W} 2 \mathrm{H}$ ajuda a obter respostas que clareiam cenários e ajudam a organizar e sistematizar ideias. Basicamente, o desenrolar da ferramenta 5W2H requer respostas para sete perguntas, que funcionam como palavraschave (em inglês) sobre o projeto a ser desenvolvido. As perguntas são: WHAT - o que será feito? WHY - Por que será feito? WHERE - onde será feito? WHEN - quando será feito? WHO: por quem será feito? HOW: como será feito? HOW MUCH: quanto custará?.

O empreendedor tem por características a capacidade de idealizar projetos, porém, muitos deles não conseguem articular suas ideias e, para isto o 5W2H é ideal, pois consegue de maneira organizada colocar no papel tudo que foi idealizado. Como o seu roteiro consiste em responder as sete questões, acima, elencadas, fica muito mais fácil montar um plano de ação, coerente e que possa de fato ser adotado dentro de seu empreendimento. Porém, as atividades mais comuns nas quais a ferramenta é aplicada são:

- Criação de plano de ação: o 5W2H pode auxiliar na elaboração de plano de ação para resolver um problema ou atingir determinado objetivo ou meta. Este é usado na tratativa de não conformidade.

- Definição de um processo ou projeto: o uso do $5 \mathrm{~W} 2 \mathrm{H}$ pode funcionar como um guia para identificar e orientar a definição das atividades de um processo ou projeto.

- Elaboração do planejamento estratégico: Tendo em vista que o planejamento estratégico trata da definição de objetivos e estratégias da organização, o $5 \mathrm{~W} 2 \mathrm{H}$ pode ser empregado para planejar e guiar ações estratégicas dentro da empresa que possibilitem o aumento da competitividade da organização e o alcance das metas estabelecidas.

As perguntas que a ferramenta apresenta respondem pontos fundamentais da execução e ajudam a garantir que nenhuma etapa ou atividade seja esquecida ou deixada de lado. Entretanto, é importante ressaltar que toda atenção é necessária durante a execução da ferramenta, pois por se tratar de perguntas relativamente simples, requer muita atenção nas respostas onde, a omissão de dados, podem interferir nos resultados esperados e, por consequência, não serem alcançados. 


\section{MATERIAIS E MÉTODOS}

O delineamento das investigações se deram nas seguinte etapas: Entrevista com produtores rurais e observações no campo de pesquisa, que no caso foram os açaizais, com a finalidade de colhermos o máximo de informações sobre as etapas do fluxo produtivo agrícola, desde a preparação da terra, plantio, colheita e escoamento da matéria-prima. Entrevista com o Gestor local do IDAM, que nos deu informações sobre o papel dos órgãos, quanto aos incentivos na expansão do setor primário. E por fim, entrevista com os proprietários de duas empresas locais beneficiadoras de açaí, para entendermos como funciona cada etapa do processo produtivo na cadeia industrial. Como ferramenta para aferição da gestão da qualidade, optamos por aplicar 3 ferramentas, que ao nosso ver melhor se adequa ao que nos propomos a pesquisar, que foram: Fluxograma, onde nos proporcionou um visão ampla, de todas as fases do processo da cadeia produtiva; o Diagrama de Ishikawa, que nos levou a entender a causa real do problema e identificar suas especificidades com relação ao ineficiência no fluxo de produção e, por fim, o $5 \mathrm{~W} 2 \mathrm{H}$ onde construímos um plano de ação (sugestão), com o objetivo de amenizar a problemática encontrada. Portanto, o conjunto destas estratégias nos proporcionou um conhecimento maior com o tema, já que desenvolvemos a pesquisa in lócus, de modo que os fatos descritos aqui foram retirados da realidade local, com observações participante que nos propiciou uma visão mais apurada com relação as etapas do fluxo produtivo, cadeia produtiva e logística de transporte, que culminou neste artigo.

Aplicação do estudo e análise dos resultados: Anori está entre os municípios em ascensão comercial, quando se trata de melhorias na produção do açaí. Nos tópicos acima podemos perceber o quanto esse município evoluiu na produção e comercialização do produto, no entanto, observamos na pesquisa de campo que muita coisa precisa ser alinhada, para que de fato este município possa expandir e se destacar no mercado. Neste tópico, iremos descrever as nossas percepções mediante as análises realizada. O município de Anori, é composto por terras de várzea e terra firme, onde determinada época do ano $80 \%$ da cidade é alagada, principalmente, nas grandes cheias do rio Solimões. Este fenômeno ocorre anualmente e, dependendo do fluxo das enchentes a cidade contabiliza suas perdas. A relação das cheias com o plantio do açaí, são bastante observadas pelos agricultores, que preferem plantar os perfilhos, na estiagem, pois segundo eles a terra fica mais fértil e propicia ao cultivo, diminuindo os riscos de perdas.

As palmeiras de açaí plantadas no município são unicaules da espécie juçara (euterpe edulis) e Euterpe Precatória, estas se adequam melhor a região onde o clima é tropical chuvoso, úmido /quente. A palmeira juçara, se diferencia da (Euterpe oleracea) pelo fato da palmeira juçara ser unicaule, como já foi falado e a segunda, nascer em touceira, ou seja, com vários perfilhos em uma só planta. Embora o fruto juçara (euterpe edulus) seja muito parecido com os da Euterpe oleracea, aos quais se originam o açaí, o Juçara e o Euterpe Precatória agregam muito mais valores nutricionais do que a outra espécie supracitada. Com base nas observações, verificamos que o processo produtivo do açaí acontece de forma gradual no município e, basicamente, ocorre em duas cadeias: a agrícola, que envolve todas as funções relacionadas ao cultivo, manejo, irrigação, colheita, debulha e ensacamento.
E a segunda é a industrial, que consiste na transformação da matéria-prima em produtos propicio ao consumo. Na figura $1 \mathrm{e}$ 2 , traz um demonstrativo de como funciona o fluxo produtivo do açaí especificando as duas cadeias:

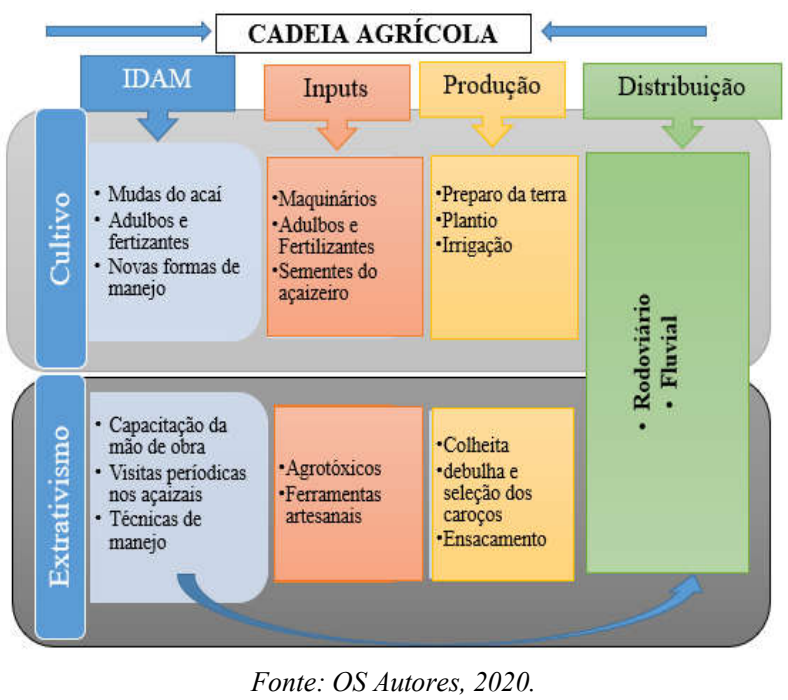

Fig. 1: Estrutura do Fluxo produtivo do açaí na Cadeia Agrícola anoriense

O demonstrativo da figura acima, faz uma explanação ampla dos Inputs/Output (entrada e saída), dos principais segmentos da cadeia produtiva Agrícola. Como podemos perceber as etapas descritas correspondente a cada segmento, faz com que se perceba a forma de como são aplicadas as tarefas relacionadas ao cultivo e ao extrativismo no município de Anorí. O primeiro elo descreve as ações realizadas pelo IDAM (Instituto de Desenvolvimento do Amazonas), à agricultura familiar, onde o suporte técnico ao setor primário tem se mostrado de grande valia aos agricultores, umas vez que os técnicos, fazem todo um acompanhamento na área a ser plantada, auxiliando na melhor forma de cultivo do açaí: medição da área plantada, percentual de pés de acordo com o hectare, adubagem, utilização de medidas contra pragas, irrigação, entre outros (GERENTE IDAM, ANORI). O IDAM desenvolve vários projetos no município de Anori, na área de suporte e estímulo ao plantio do açaí, dentre eles o fornecimento de perfilhos para o manejo adequado na área de cultivo. Segundo o Gerente Local, Moisés de Souza Bruno, são cadastrados na instituição em torno de 100 produtores de açaí, e estes recebem visitas periódicas do técnico em seus açaizais, para fazer a avaliação, para que no futuro, este produtor consiga obter palmeiras muito mais frutíferas e com melhor qualidade.

Por ter um clima tropical úmido e, ser atingidas anualmente pelas cheias do rio Solimões, as terras anorienses são mais propícias a produção de açaí de melhor qualidade, uma vez que ao sair da estiagem, as terras estão fertilizadas para um novo ciclo de produção, assim como para novos plantios. Em Anorí, existe um grande percentual de açaizais em áreas de várzea, que necessita de novos planejamentos por parte do técnico, tanto no trato com a terra, como no ciclo de produção e colheita, já que periodicamente, as áreas são tomadas pelas cheias. Na etapa input agrícola, envolve todos os aparatos na questão de insumos para o plantio: maquinário, adubo e fertilizantes, seleção da semente, ferramentas artesanais e industriais. Nas áreas pesquisadas, observamos que o cuidado com a terra (etapa de produção) por parte dos agricultores, faz 
toda diferença no resultado final, no entanto, poucos produtores utilizam ferramentas industriais, o que dificulta e atrasa o tempo de plantio. Segundo o técnico local Mario Jorge Grijó, "cada hectare suporta aproximadamente, 400 pés de açaí que, basicamente, renderiam 100 sacos de açaí por hectare". A Embrapa (2002) enfatiza que, a qualidade da semente, resulta numa melhor qualidade dos frutos e com isso uma maior durabilidade no processamento, resultado de uma forma adequada de fertilização da terra e técnicas de irrigação eficiente, principalmente, em períodos sazonais, promovendo maior qualidade e menor perdas dos perfilhos. Vale ressaltar que, a etapa de Produção é a parte mais importante da cadeia agrícola, pois nela envolve o resultado final da produção que vai desde o plantio (cultivo) até a colheita, debulha, seleção dos caroços e ensacamento (extrativismo). Para esse processo é necessário o deslocamento dos produtores para a área de cultivo, pois no próprio local da colheita, que no município é feito de forma artesanal: usa-se a "peconha" (que é uma amarração de um tecido resistente, colocado nos pés dos apanhadores) este utensílio dar apoio para subir nas palmeiras com maior rapidez. Neste processo, os riscos são eminentes, pois coloca o apanhador em contado direto com a palmeira que, chega há até 25 metros de altura. Há relatos, de vários acidentes no município relacionados a queda de açaizeiro, seja ele pela quebra da palmeira ou pela perca de apoio dos apanhadores.

Outro processo de produção é a debulha e seleção dos caroços, pois é necessário fazê-lo no local da colheita, onde se retira os frutos dos cachos para assim descartar os frutos impróprio e ensacar os adequados ao despolpamento. Outro fator importante é que em Anori, não há cooperativas, ou seja, os produtores negociam direto com os beneficiadores. A etapa de distribuição, está relacionada a logística que ainda é um dos gargalos quando se fala de estratégias para uma melhor escoação da matéria-prima. A logística para Martins e Alt (2006) consiste em três dimensões principais: a primeira dimensão está relacionada ao fluxo (suprimentos, transformação, distribuição e serviço ao cliente), a segunda dimensão refere-se ao administrativo (processo operacional, administrativo, de gerenciamento e de engenharia) e a terceira é a dimensão de domínio (gestão de fluxos, tomadas de decisão, gestão de recursos e modelo organizacional). Nesta perspectiva, a logística de transporte é uma das principais ferramentas para melhor escoar o açaí. A outra cadeia diz respeito a cadeia Industrial, onde a figura 2 demonstra a estrutura corresponde à realidade local dentro desta cadeira:

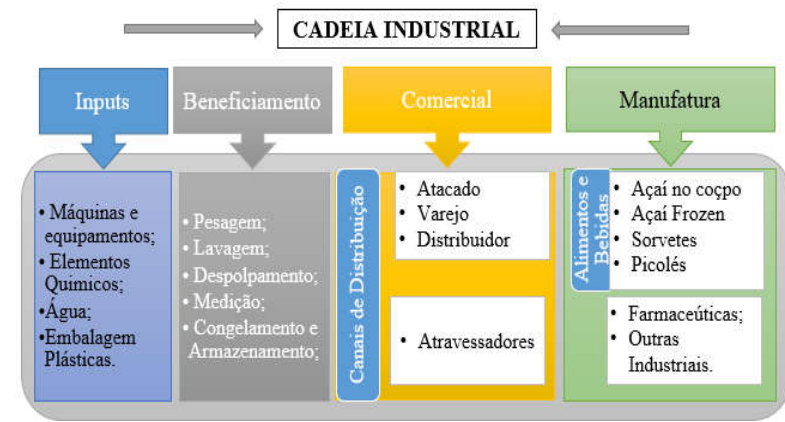

Fonte: OS Autores, 2020.

Fig. 2: Estrutura do Fluxo produtivo do açaí na Cadeia Industrial anoriense

O outro segmento, diz respeito a cadeia industrial. A figura acima, foi estruturada nos moldes da cadeia industrial operada no município de Anorí.
Nela, o primeiro elo se refere aos inputs industriais: máquinas e equipamentos, elementos químicos, água e embalagens plásticas. Estes insumos são importantes na cadeia produtiva, pois através deles a empresa consegue maquinários necessário para o processamento do açaí. Anori não possui grandes industrias neste ramo, o que há são pequenas empresas que trabalham neste setor, que são as chamadas "Açailândia". Elas pertencem ao segundo elo da cadeia, que é o beneficiamento, responsável pela pesagem, lavagem, despolpamento, medição (em litros) e armazenamento. Vale ressaltar que Anori, possui dois modais de Distribuição: Rodoviário e o fluvial, que são essenciais tanto na figura 1, quanto na figura 2. O modal rodoviário, neste cenário, é responsável tanto pelo transporte da matéria-prima dos açaizais até as industriais de beneficiamento, quanto pelo transporte do produto, já processado, até os barcos. A maior dificuldade na questão logística está relacionada a falta de infraestrutura das estradas que dão acesso aos açaizais.

O produtor José Maria Moraes, destacou ser esta uma das maiores dificuldades na escoação da matéria-prima. Segundo ele, o tempo entre a colheita e o escoamento, é contado de forma regressiva devido a pericividade do fruto a partir de sua retirada das palmeiras e, em épocas de inverno, a estrada se torna intrafegável para carros menores, permitindo somente a retirada por meio de caçambas o que dificulta a agilidade no transporte, resultando em perdas devido a chegada das más condições dos caroços nos pontos de beneficiamento. Ching (2001), ressalta que a estrutura de distribuição deve responder a quatro questões: como, quanto, quando e quem irá transportar. Entre Dezembro (2019) a março (2020), analisamos o fluxo produtivo de duas Açailândia que mais se destacam no mercado, no município de Anori: Vovô Sales e R.S açaí da Amazônia. Quanto aos inputs industriais elas possuem máquinas de processamento, que no caso da Vovô Sales, possui 4 máquinas e R.S açaí da Amazônia possui três máquinas; água, que no caso de ambas possuem poços artesianos e; embalagens plásticas, que servem para embalar o produto final, medindo 1 litros.

Vale ressaltar que, a empresa de beneficiamento Vovô Sales conta com 15 colaboradores, enquanto que a R.S Açaí da Amazônia possui 12 colaboradores que prestam serviços, executando funções como batedores que são responsáveis pela lavagem e despolpamento; a equipe responsável pela medição e amarração das sacolas plásticas, litro a litro; e armazenagem, que neste caso são acondicionadas em caixas de isopor, utilizando gelo para o acondicionamento do produto In natura, para serem enviados à capital. A etapa Comercial, que faz parte do sistema logístico, analisada na figura acima, elencamos como parte deste elo o atacado, varejo, distribuidores e atravessadores. As duas Açailândia trabalham dentro dessa estrutura de comercialização, onde os produtos são vendidos, em Manaus, tanto no atacado (revendedores), quanto no varejo. Os distribuidores, nesta cadeia são responsáveis pela entrega do produto aos revendedores e a pessoas que buscam adquirir o produto em pequena quantidade. Como Manaus é o principal ponto de distribuição, o acesso a capital é feito somente por vias fluviais (barcos de médio porte - atravessadores), já que não possui rodovias de acesso entre o município e a capital. O primeiro elo da cadeia logística é a área comercial. É ela, conjuntamente com a área de marketing, quem capta o desejo latente ou já explicito do consumidor e o uso dos recursos que dispõe ao torná-lo realidade, estabelecer uma relação biunívoca permanente com 
ele. Assim, não se trata de estabelecer uma transação eventual, mas um veículo. (CAMPOS, 2009, P.335). Dentro dessa lógica, o açaí já processado precisa ser comercializado daí a necessidade das atividades de marketing e seus canais de distribuição, para se chegar a mesa do consumidor final, cliente. Este é o alvo de toda cadeia produtiva desde o cultivo aos pontos de distribuição, que em Anorí, o maior ponto de distribuição é a capital Manaus, onde $70 \%$ do produto produzido nas Açailândia são escoados para a cidade, sendo vendidos em feiras, supermercados e em pequenas vendas autônomas.

O último elo refere-se a manufatura, onde o açaí ganha novos mercados, como sorvetes, Frozen (açaí pastoso, agregado leite, farinha tapioca, granola e demais cereais), sorvetes, dindins (açaí adoçado, diluído em água e colocados em pequenos saquinhos). Assim, o output (saída) da cadeia do açaí, gera inputs para novos mercados, que neste caso são as industriais farmacêuticas, que desenvolvem pesquisas científicas para agregar valor nutricionais aos insumos provenientes do açaí.

Em entrevista com os dois proprietários das empresas supracitadas, foram levantadas algumas questões consideradas importantes para corroborar com o que já foi mencionado. A primeira delas foi relacionada ao fluxo de processos de despolpamento do açaí, desde a chegada da matéria-prima na empresa à ensacagem e armazenamento.

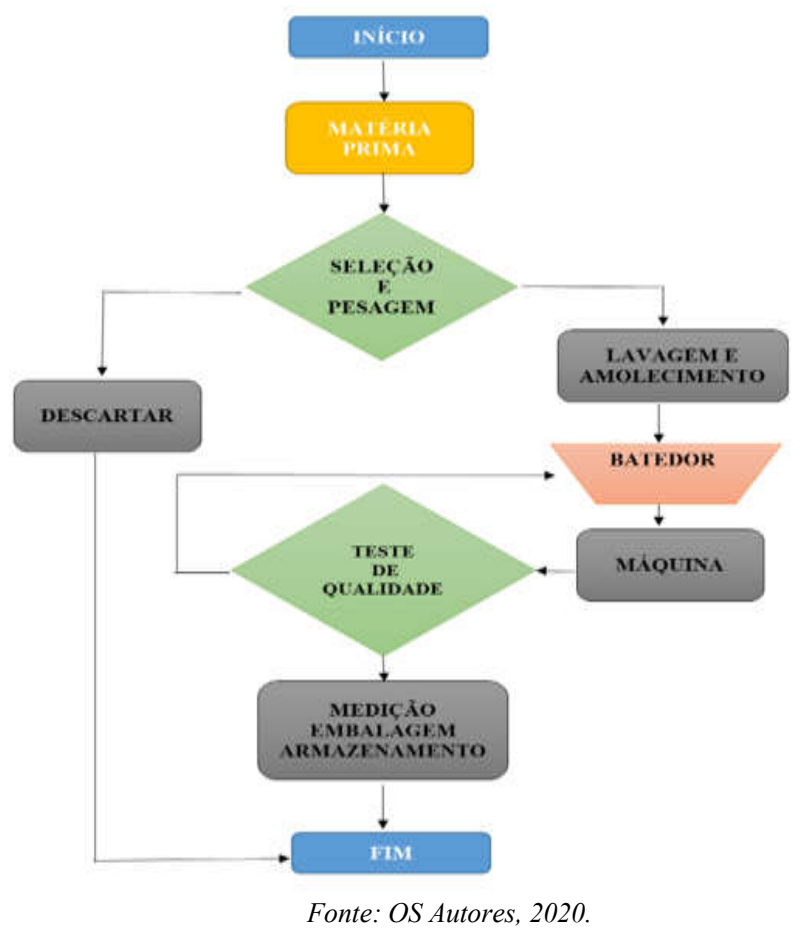

Fig. 3: fluxo de processo do açaí na Açailândia de Anori

Ao analisar o fluxo de processos deste modal, podemos perceber que há uma série de etapas a serem cumpridas para que o produto final, o açaí, venha ser de qualidade. Então, ao chegar a matéria-prima na empresa, a primeira etapa é a seleção e pesagem dos caroços: aqui há duas decisões a serem tomadas; se os caroços estiverem de boa qualidade, passa-se para etapa seguinte, se não, é descartado imediatamente. Logo após, segue-se para lavagem e amolecimento do fruto, onde os mesmos são emergidos em água morna, para facilitar a despolpagem. Depois, o batedor (funcionário responsável pelo manuseio da máquina), adiciona os caroços para serem processados.
Assim, que são processados, o vinho, como é chamado na região, passa pelo teste de qualidade; nesta etapa essa averiguação é feita pelo degustador: Se o açaí estiver com qualidade; textura e sabor, passa para a fase final, caso contrário, volta para o batedor para serem novamente processados com a adição de mais caroços, até que a textura e sabor seja ideal para o consumo. A última etapa dentro da empresa é medição por litro, fechamento das embalagens e armazenamento, para então serem comercializados. Nos preceitos de Gonçalves (2000) a definição de processo está relacionada ao conjunto de atividade que adicione valor ao input (entradas) e forneça um output (saída) dos produtos a um cliente específico, que no neste contexto, são as empresas de beneficiamento do açaí. Assim, as empresas pesquisadas possuem um fluxo de processos que são seguidos, rigorosamente, quase que diariamente. Enfatizando este pensamento, a ISO 9000, considera processos como conjuntos de atividades inter-relacionadas que transformam entradas em saídas de qualquer produto. Questionados sobre as maiores dificuldades encontradas dentro desse processo de fluxo produtivo, os beneficiadores elencaram 3 pontos negativos: Logística desalinhada, interrupção no fornecimento de energia, dificuldade de escoar na estiagem. Na figura 4, o diagrama abaixo monstra esses pontos de não conformidades.

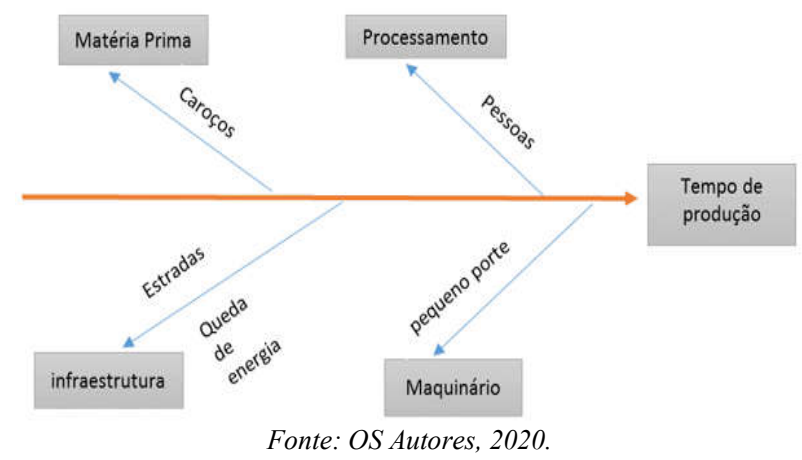

Fig. 4: Pontos de não conformidades

A figura 4, coloca dentro de um esquema as principais dificuldades encontradas pelos beneficiadores. A primeira está relacionada a qualidade da matéria-prima, pois há relatos de desperdícios logo na entrada deste produto na empresa, uma vez que na etapa de seleção, enfatizada nafigura 3, existem descartes dos insumos por atestarem má qualidade. O processamento, envolve todos os prestadores de serviços (pessoas), que no município poucos possuem qualificação profissional, sendo que a maioria aprendeu na prática o processamento da fruta. A qualificação profissional traz inúmeros benefícios à empresa, pois "Quanto maior a intensidade com que as pessoas e as organizações aprendem, mais condições existem para a criação de vantagens competitivas." (MALSCHITZKY, 2002). A infraestrutura foi mencionada pelos entrevistados, sendo um dos pontos crucias que afetam negativamente o processo produtivo do açaí: as más condições da estrada, se torna um empecilho no momento de escoar o produto dos açaizais, causando atrasos e perdas da matéria-prima. Em Anori, a estrada de acesso está em más condições de trafegabilidade, devido à falta de recapeamento por parte da gestão municipal e estadual. Outro fator negativo, é a queda constante no fornecimento de energia, o que causa transtornos tanto para os produtores, quanto para os beneficiadores, pois, uma vez cortado o fornecimento toda produção a empresa para de funcionar, sendo este um ponto crucial, segundo eles, já que o açaí é um produto altamente 
perecível e precisa ser processado em tempo hábil, para não perder a qualidade. As máquinas processadoras nas Açailândia de Anori são, basicamente, de pequeno porte onde cada uma suporta processar meia saca, que equivale a aproximadamente, 25 quilos de caroços por vez, o que atrasa a produção sendo preciso várias etapas para processar a quantidade desejada. Questionados sobre investimentos em máquinas maiores, os entrevistados, colocaram a falta de operadores capacitados como o principal empecilho. Diante do exposto, consegue-se perceber toda as etapas do processo relacionado ao fluxo produtivo do açaí no município de Anori, onde buscamos pontuar dados reais colhidos na própria realidade para que pudéssemos trazer as reais informações relacionadas ao tema. Após toda essa abordagem, onde foram colocados os pontos principais da cadeia produtiva, observamos vário pontos de não conformidades, dentro dessa realidade, onde elaboramos um plano de ação que possa minorar algumas das dificuldades encontradas.

O plano de ação a seguir, tem por objetivo capacitar a mão-deobra dos operadores (batedores) que manuseiam as máquinas, para que os mesmos possam operar máquinas de grande porte. Esta capacitação melhorará tanto na ampliação da produção, quanto reduzirá o tempo de produção, fazendo com que a empresa possa produzir mais produtos em uma escala menor de tempo e com maior qualidade.

Tabela 1: Plano de Ação/Capacitação da mão-de-obra.

\begin{tabular}{|c|c|}
\hline O que? & Capacitar a mão-de-obra dos operadores das máquinas. \\
\hline Por que? & $\begin{array}{l}\text { Porque os operadores não sabem manusear as máquinas de } \\
\text { grande porte. }\end{array}$ \\
\hline Quem? & Os funcionários que executam funções de batedores de açaí. \\
\hline Quando? & No início da safra (setembro/outubro) \\
\hline Onde? & No próprio município \\
\hline Como & Em parceria com IDAM, CETAM e poder executivo. \\
\hline Quanto? & Curso técnico 300 (cada) X 5 batedores $=1.500,00$ \\
\hline
\end{tabular}

O delineamento da ação proposta, poderá ser ampliada a todos os beneficiadores de açaí, onde aquele profissional melhor capacitado, com certeza produzirá muito mais e com uma melhor qualidade. Clein, Toledo e Oliveira (2013), destaca que a empresa pode e deve oportunizar qualificação profissional a seus colaboradores ou até mesmo custear parcialmente os cursos mais relevantes, para um melhor serviço prestado. Nesta proposta, colocamos a prefeitura municipal de Anori como parceira da ação, para que possa custear tal curso, de modo a ampliar a capacitação de todos os prestadores de serviços na área do açaí, como incentivo a capacitação profissional daqueles que não tem condições financeira de pagar tal curso, criando oportunidade as famílias ribeirinhas de obter um curso profissionalizante, que é tão importante neste setor.

\section{Considerações Finais}

Após as análises podemos mencionar que de fato o açaí em Anori, se tornou uma importante fonte de renda no setor do agronegócio, com grande eminencia de projeção para grandes negócios na área de suprimentos. O açaí de Anori, como é conhecido em toda Manaus, vem ganhando espaço considerável no mercado, por sua qualidade. Nas feiras, barracas, supermercados, entre outros, é facilmente comercializado gerando fonte de renda considerável, principalmente, para os autônomos que viram neste negócio uma nova oportunidade de renda.
Anori, ano a ano vem se destacando no mercado tanto pelo aumento da produção da matéria-prima, quanto pela qualidade dos frutos retirados das palmeiras, o que agrega valor a polpa extraída sendo esta, de sabor autêntico e de textura muito mais condensada se tornando preferência na mesa do cliente. Este valor agregado ao açaí se torna um diferencial quando se tem no mercado uma competitividade por maiores adesão da clientela, sendo ele fornecedores, varejista ou atacadistas. A logística neste mercado, se torna um grande divisor de águas entre a eficiência $\mathrm{x}$ ineficiência, a empresa que possui um modal logístico a contento, consegue cumprir os prazos com maior rapidez, que no caso do açaí se torna primordial, por ser um produto altamente perecível. Qualquer ineficiência no transporte, seja ele, nos açaizais, nas empresas de beneficiamento ou atravessadores, pode causar prejuízos irreparáveis, já que uma falha ocorrida em um deste elos pode causar perca total ou parcial do produto.

Após estudos dos dados obtidos, percebemos que há uma série de fatores que precisam ser ajustados para uma melhor qualidade no produto final: a principal delas, diz respeito a qualificação profissional, uma vez que os colaboradores das duas empresas pesquisadas, não possuem curso técnico para o manuseio das maquinas, causando de certas forma desajuste na qualidade do produto, ou seja, falta padronização no produto final. Esperamos que este trabalho venha despertar nos novos pesquisadores $o$ interesse por desenvolver pesquisas relacionadas a este tema, de modo que possa ser cada vez mais difundido as riquezas de nossa região, colocando o açaí de Anori, em destaques nos enunciados dos temas de pesquisas, ampliando cada vez mais a área de conhecimento de um produto facilmente encontrado, porém, com poucas pesquisas que evidenciam as origens do "ouro negro" amazônico.

\section{Agradecimentos}

Ao Instituto Metropolitano de Ensino - IME/ FAMETRO.

\section{REFERÊNCIA}

Arbage, A. P. 2004. Custos de transação e seu impacto na formação e gestão da cadeia de suprimentos: estudo de caso em estruturas de governança híbridas do sistema agroalimentar no rio grande do Sul. Tese Doutorado (em Administração), UFRGS, Porto Alegre.

Bowersox, Donald J., Closs, David J. Logística empresarial: o processo de integração da cadeia de suprimento. São Paulo: Atlas, 2001.

Campos, V. F. Gerenciamento da rotina do dia-a-dia. Belo Horizonte: INDG Tecnologia e Serviços Ltda, 2004.

Ching, Hong Yuh. Gestão de estoques na cadeia logística integrada - Supply Chain. 2a ed.São Paulo: Atlas, 2001.

Christopher, M. Logística e Gerenciamento da Cadeia de Suprimentos: criando redes que agregam valor; [tradução Mauro de Campos Silva] - $2^{\mathrm{a}}$ ed - São Paulo: Thomson Learning, 2007.

Clein, Claudelir; Toledo, Milka Inês K. de; Oliveira, Lindomar S. de. Qualificação e Capacitação: investir no capital humano como forma de crescimento e vantagem competitiva. 2013.

Crosby, P. B. Qualidade é Investimento. Rio de Janeiro: José Olympio: 1986.

Embrapa. Açaí: produção de frutos, mercado e consumo. Disponível em: $<$ https://www.embrapa.br/busca-de- 
publicacoes/-/publicacao/1059773/acai-producao-defrutosmercado-e-consumo>. Acesso em: 12 Dezembro, 2019.

Galotta, Ana Lúcia Queiroz de Assis. Departamento de Química, Instituto de Ciências Exatas, Universidade Federal do Amazona. Quim. Nova, Vol. 28, No. 4, 610613, 2005.

Gama, José Ricardo Vasconcelos; Botelho, Soraya Alvarenga; Bentes-Gama, Michelliny de Matos e Scolforo, José Roberto Soares. Estrutura e potencial futuro de utilização da regeneração natural de floresta de várzea alta no município de Afuá, Estado do Pará. Ciência Floresta, 13(2):71-82. 2003.

Gasnier, Daniel G. A dinâmica dos estoques: guia prático para planejamento, gestão de materiais e logística. São Paulo: IMAM, 2002. 316p.

Gil, Antonio Carlos. Como elaborar projetos de pesquisa. 5. ed. São Paulo: Atlas, 2008.

Gonçalves, Thiago. Análise da Cadeia Produtiva do Açaí: Uma abordagem voltada ao Estudo dos Componentes de Desempenho Logístico. 2012. Disponível em: Acesso em: 18 nov. 2019.

Heinrich, M., Dhanji, T., Casselman,I. Açaí (Euterpe oleracea Mart.) - A phytochemical and pharmacological assessment of the species' healthclaims. PhytochemistryLetters, v. 4, p.10-21, 2011.

Henkel Karl, Amaral, Idême Gomes Análise agrossocial da percepção de agricultores familiares sobre sistemas agroflorestais no nordeste do estado do Pará, Brasil, 2008.

Homma, Alfredo K. O. et al. Açaí: Novos Desafios e Tendências. Belém, 2006.

Ibge - Instituto Brasileiro DE Geografia E Estatística, 2010. Pesquisa Nacional por Amostra de Domicílios: síntese de indicadores 2001. Rio de Janeiro: IBGE. IBGE - Instituto Brasileiro de Geografia e Estatística, 1998.
Malschitzky, Nancy. Empregabilidade x Empresabilidade. O ambiente empresarial deve estimular o desenvolvimento profissional. Revista FAE Business, $n^{\circ}$ 2, junho/2002.

Rezende, André. O que é realmente qualidade de um produto. Empreendedor Enevoar prática, 2012.

Rodrigues, M.V. Ações para a qualidade: gestão estratégica e integrada para a melhoria dos processos na busca da qualidade e competitividade. 3. ed. Rio de Janeiro: Qualitymark, 2010.

Rogez, H. Açaí: preparo, composição e melhoramento da conservação. Belém: Universidade Federal do Pará, 2017.

Souza, Lindaurea Alves. Insetos pragas em acessos de açaizais em viveiros. Ministério da Agricultura, Pecuária e do Abastecimento, Comunicado Técnico $\mathrm{n}^{\circ}$ 75, 2002, 5p.

Tavares, G. dos S., Homma, A. K. O. Comercialização DO Açaí NO Estado DO PARÁ: Alguns Comentários. Observatório de laEconomíaLatinoamericana, set.2015.

Tonon, R.V., Brabet, C., Hubinger, M.D. Influence of process conditions on the physicochemical properties of açai (Euterpe oleraceae Mart.) powder produced by spray drying. Journal of Food Engineering. v88, n3, p411-418, 2008.

Werkema, Maria Cristina Catarino. As ferramentas da qualidade no gerenciamento de processos. 6. ed. Belo Horizonte, MG: Editora de Desenvolvimento Gerencial, $1995.106 \mathrm{p}$.

Yuyama K. L. K. O., Aguiar, J. P. L., Silva Filho, D. F., Varejão, M. J., Fávaro, D. I. T., Vasconcellos, M. B. A., Pimentel, S. A., Caruso, M. S. F. Caracterização físicoquímica do suco de açaí de Euterpe precatória Mart. Oriundo de diferentes ecossistemas amazônicos. Acta Amazônica, 2011. 